\title{
Exames complementares no diagnóstico da tuberculose em bovinos reagentes à tuberculinização comparada
}

\author{
Comparison of complementary diagnostic methods \\ of bovine tuberculosis on skin-test reactive cattle
}

\author{
Mariana Assunção de Souza' *, Nadia Grandi Bombonato', Pollyanna Mafra Soares', \\ Gabriela Bim Ramos' ${ }^{1}$, Igor Paula Castro², Alessandra Aparecida Medeiros², Anna Monteiro Correia Lima'
}

RESUMO: Objetivou-se com este estudo comparar diferentes métodos complementares de diagnóstico (macroscópico, histopatológico, sorológico e molecular) da tuberculose, em bovinos naturalmente infectados. O trabalho deu-se por meio de amostras colhidas em abate sanitário de 40 bovinos reagentes no teste cervical comparativo (TCC) para tuberculose. A inspeção macroscópica post mortem das carcaças foi acompanhada de colheita de amostras de muco nasal, sangue e tecido (fígado, pulmão e linfonodo mediastínico) para realização do exame de reação em cadeia pela polimerase (PCR), de Enzyme-Linked Immunosorbent Assay (ELISA) e histopatológico com coloraçóes de hematoxilina-eosina (HE) e Ziehl-Neelsen (ZN), respectivamente. Dos 40 bovinos inspecionados no abate, 22 (55\%) animais apresentaram algum tipo de lesão macroscópica sugestiva de tuberculose. Nos achados histopatológicos visualizados em HE, 13 $(32,5 \%)$ carcaças apontaram alteraçóes histológicas, sendo $6(15 \%)$ nos linfonodos mediastínicos, 5 (12,5\%) no fígado e $3(7,5 \%)$ no pulmão. Não foi observada a presença de bacilos álcool-ácido resistentes em nenhuma das amostras avaliadas. O ensaio sorológico de ELISA/IDEXX identificou um (2,5\%) animal reagente, e o teste de PCR detectou DNA de Mycobacterium bovis em uma (2,5\%) amostra. Concluiu-se que entre os exames complementares de diagnóstico avaliados nenhum foi capaz de detectar todos os animais que estavam positivos na tuberculinização, porém a associação de diferentes métodos pode garantir a confiabilidade do diagnóstico.

PALAVRAS-CHAVE: bacilo álcool-ácido resistente; ELISA; Mycobacterium bovis; reação em cadeia pela polimerase; histopatologia.

\begin{abstract}
The aim of this study was to compare different complementary diagnostic methods (macroscopic, histological, serological and molecular) of tuberculosis in naturally infected cattle. The study was conducted from samples taken from 40 reagents cattle in cervical comparative intradermal tuberculin test (ITT). The macroscopic post mortem inspection of carcasses was followed by the collection of nasal swabs, blood and tissue samples (liver, lung and mediastinal lymph node) for polymerase chain reaction (PCR) test, Enzyme-Linked Immunosorbent Assay (ELISA) and histopathologic test with hematoxylin-eosin (HE) and Ziehl-Neelsen (ZN), respectively. Of the 40 cattle slaughtered, $22(55 \%)$ carcasses had macroscopic lesions suggestive of tuberculosis. The histopathology HE identified 13 (32.5\%) carcasses with histological changes: $6(15 \%)$ in the mediastinal lymph nodes, $5(12.5 \%)$ in the liver and $3(7.5 \%)$ in the lung. At $\mathrm{ZN}$, the presence of acid-fast bacilli was not detected in any of the samples tested. The ELISA/IDEXX ${ }^{\circ}$ identified one $(2.5 \%)$ reagent animal, and the PCR test detected DNA of Mycobacterium bovis in one (2.5\%) cow. It is concluded that among the diagnostic methods reviews none was able to detect all animals that were positive in tuberculin test, but the association of different methods can ensure diagnostic accuracy.
\end{abstract}

KEYWORDS: Acid-fast bacilli; ELISA, Mycobacterium bovis; polymerase chain reaction; histopathology.

\footnotetext{
'Centro Colaborador de Defesa Agropecuária do Brasil Central e Laboratório de Doenças Infectocontagiosas; Faculdade de Medicina Veterinária; Universidade Federal de Uberlândia (UFU) - Uberlândia (MG), Brasil.

${ }^{2}$ Laboratório de Patologia Animal; Faculdade de Medicina Veterinária; UFU - Uberlândia (MG), Brasil.

*Autor correspondente: mari_assuncao@yahoo.com.br

Recebido em: 17/07/2014. Aceito em: 05/04/2016
} 


\section{INTRODUÇÃO}

A tuberculose bovina, doença causada pelo Mycobacterium bovis, é uma zoonose cujo hospedeiro primário é o bovino. Constitui uma significativa causa de condenação de carcaças em matadouros, resultando em grande perda econômica (MicHeL et al., 2010). Por conta do impacto sobre o comércio internacional, da natureza contagiosa e das implicaçôes para a saúde humana, programas de controle e erradicação da doença são aplicados em todo o mundo (Medeiros et al., 2010).

$\mathrm{O}$ teste intradérmico da tuberculina, que avalia a resposta imune celular, éo método padrão para o diagnóstico da tuberculose bovina e é utilizado em diferentes países, porém cada país estabelece seu próprio protocolo para uso e interpretação, baseado nas circunstâncias locais e na fase dos programas (OIE, 2013). A cinética de desenvolvimento da reação de hipersensibilidade tardia em bovinos infectados pode ser identificada pelo exame com apenas três semanas pós-infecção (WATRELOT-Virieux et al., 2006).

No entanto, testes intradérmicos não são $100 \%$ específicos (MONAGHAN et al., 1994; AAGAARD et al., 2010), e a ocorrência de reaçôes falso-positivas, com o abate desnecessário do animal, muitas vezes coloca em risco a credibilidade de todo o programa de controle. Assim, a confirmaçáo de animais reativos por intermédio de outros métodos muitas vezes se faz necessária para garantir a confiabilidade do diagnóstico (FráguAs et al., 2008).

Vários métodos complementares estão disponíveis e consistem em avanços para o diagnóstico e o controle da tuberculose bovina. Entre eles, encontram-se os ensaios ante mortem como o exame clínico, o ensaio de IFN-g, os testes sorológicos como o Enzyme-Linked Immunosorbent Assay (ELISA) e os ensaios post mortem, como o diagnóstico de lesôes macroscópicas, o exame microscópico da lesão e o isolamento em cultivo. Os métodos moleculares utilizam ferramentas de reaçôes em cadeia pela polimerase (PCR) (WATERs et al., 2011; Furlanetto et al., 2012; OIE, 2013).

Apesar de diversos métodos de diagnóstico terem sido desenvolvidos, nenhum deles pode ser empregado isoladamente, havendo sempre a necessidade do uso de técnicas complementares para o alcance da informaçáo eficaz e completa (RUGGiero et al., 2007).

Diante disso, objetivou-se com este estudo comparar diferentes métodos complementares de diagnóstico (macroscópico, histopatológico, sorológico e molecular) da tuberculose, em bovinos naturalmente infectados.

\section{MATERIAL E MÉTODOS}

\section{Amostras}

O material de análise deste estudo foi obtido em um abate sanitário, no matadouro e frigorífico Frisago Frigorífico São
Gotardo LTDA. (Serviço de Inspeção Estadual n. ${ }^{\circ}$ 3.957), de São Gotardo, Minas Gerais. Colheram-se amostras de 40 bovinos positivos no teste cervical comparativo (TCC) para tuberculose. Os resultados do exame de tuberculinização comparada encontram-se na Tabela 1.

Amostras de muco nasal foram colhidas no momento pós-insensibilização dos animais, por meio de swab de algodão estéril (Figueiredo et al., 2010). Os swabs foram acondicionados em tubo Falcon estéril $(15 \mathrm{~mL})$ contendo $3 \mathrm{~mL}$ de solução salina $(0,9 \%)$ e transportados refrigerados $\left(2\right.$ a $\left.8^{\circ} \mathrm{C}\right)$ ao Laboratório de Doenças Infectocontagiosas (LADOC) da Faculdade de Medicina Veterinária (FAMEV) da Universidade Federal de Uberlândia (UFU), Minas Gerais.

As amostras de sangue foram colhidas durante a sangria, em tubo tipo Falcon estéril $(15 \mathrm{~mL})$ sem anticoagulante. $\mathrm{O}$ material foi transportado refrigerado $\left(2\right.$ a $\left.8^{\circ} \mathrm{C}\right)$ ao LADOC-FAMEV-UFU e centrifugado a $3.000 \mathrm{~g}$ por $5 \mathrm{~min}$. Em seguida, as amostras de soro foram acondicionadas em criotubos e congeladas a $-20^{\circ} \mathrm{C}$ até a realização dos exames.

Durante a inspeçáo macroscópica realizada de acordo com as normas vigentes no Regulamento da Inspeção Industrial e Sanitária de Produtos de Origem Animal (RIISPOA) (BrasIL, 1962), as lesôes sugestivas de tuberculose foram registradas e fotografadas. Fragmentos de aproximadamente $1,5 \mathrm{~cm}$ de fígado, linfonodo mediastínico e pulmão foram colhidos e armazenados em frasco plástico estéril com formol tamponado a $10 \%$ (Jones et al., 2000). Colheram-se as amostras independentemente de apresentarem ou não lesóes sugestivas de tuberculose.

\section{Testes de diagnóstico}

Para o diagnóstico histopatológico, após a fixação das amostras em soluçáo formol a $10 \%$ por período mínimo de 48 horas, elas foram seccionadas de maneira que cada fragmento com lesão constituísse todas as camadas do granuloma, isto é, a transição entre a lesão e o tecido aparentemente normal, a cápsula e o tecido necrótico. Em seguida, tais amostras foram submetidas às técnicas rotineiras de desidratação, diafanização, clarificação e inclusão em parafina. Por fim, foram feitos cortes de $4 \mu \mathrm{m}$ em micrótomo (Leica RM2125) e obtidas duas lâminas histológicas de cada bloco. Uma lâmina foi submetida à coloração de hematoxilina-eosina, com o objetivo de se visualizar as alteraçóes histológicas, e a outra à coloração de Ziehl-Neelsen, para que fosse investigada a presença de bacilos álcool-ácido resistentes (BAAR) (Tolosa et al., 2003).

Para o diagnóstico sorológico, empregou-se kit comercial de ELISA/IDEXX ${ }^{\circledast}$ Mycobacterium bovis antibody test. O exame foi realizado segundo instruçôes do fabricante e os resultados avaliados pelo programa $\mathrm{xChek}^{\circledR} 3.3$ (IDEXX Laboratories). A interpretação dos resultados foi determinada pela relação da 
Tabela 1. Resultado do exame de tuberculinização de 40 bovinos reagentes no teste cervical comparativo. Os resultados são expressos em mm e interpretados de acordo com a tabela do regulamento técnico do Programa Nacional de Controle de Erradicação da Brucelose e Tuberculose Animal (PNCEBT).

\begin{tabular}{|c|c|c|c|c|c|c|c|c|}
\hline Amostra & AO & A72 & $\Delta \mathrm{A}$ & BO & B72 & $\Delta \mathrm{B}$ & $\Delta \mathrm{B}-\Delta \mathrm{A}$ & Resultado \\
\hline 1 & 6,2 & 9,0 & 2,8 & 8,2 & 15,2 & 7,0 & 4,2 & positivo \\
\hline 2 & 6,0 & 7,5 & 1,5 & 8,5 & 14,0 & 5,5 & 4,0 & positivo \\
\hline 3 & 4,6 & 5,0 & 0,4 & 7,6 & 12,2 & 4,6 & 4,2 & positivo \\
\hline 4 & 5,0 & 7,5 & 2,5 & 7,5 & 17,3 & 9,8 & 7,3 & positivo \\
\hline 5 & 5,0 & 7,0 & 2,0 & 6,7 & 13,7 & 7,0 & 5,0 & positivo \\
\hline 6 & 4,5 & 10,2 & 5,7 & 7,0 & 20,0 & 13,0 & 7,3 & positivo \\
\hline 7 & 4,7 & 5,5 & 0,8 & 7,0 & 14,8 & 7,8 & 7,0 & positivo \\
\hline 8 & 6,4 & 7,0 & 0,6 & 8,6 & 14,3 & 5,7 & 5,1 & positivo \\
\hline 9 & 5,0 & 7,0 & 2,0 & 8,5 & 14,5 & 6,0 & 4,0 & positivo \\
\hline 10 & 5,0 & 5,7 & 0,7 & 9,5 & 14,7 & 5,2 & 4,5 & positivo \\
\hline 11 & 6,0 & 7,0 & 1,0 & 7,5 & 14,5 & 7,0 & 6,0 & positivo \\
\hline 12 & 8,2 & 13,5 & 5,3 & 8,5 & 19,0 & 10,5 & 5,2 & positivo \\
\hline 13 & 4,6 & 5,7 & 1,1 & 7,0 & 12,2 & 5,2 & 4,1 & positivo \\
\hline 14 & 5,7 & 6,5 & 0,8 & 10,0 & 15,5 & 5,5 & 4,7 & positivo \\
\hline 15 & 6,5 & 10,5 & 4,0 & 9,0 & 21,0 & 12,0 & 8,0 & positivo \\
\hline 16 & 6,5 & 12,0 & 5,5 & 6,7 & 21,2 & 14,5 & 9,0 & positivo \\
\hline 17 & 7,1 & 8,1 & 1,0 & 9,5 & 15,8 & 6,3 & 5,3 & positivo \\
\hline 18 & 6,0 & 8,6 & 2,6 & 9,0 & 16,2 & 7,2 & 4,6 & positivo \\
\hline 19 & 8,5 & 12,3 & 3,8 & 8,5 & 21,0 & 12,5 & 8,7 & positivo \\
\hline 20 & 4,5 & 7,0 & 2,5 & 6,3 & 21,0 & 14,7 & 12,2 & positivo \\
\hline 21 & 6,8 & 12,5 & 5,7 & 8,1 & 20,4 & 12,3 & 6,6 & positivo \\
\hline 22 & 4,5 & 7,0 & 2,5 & 6,3 & 18,8 & 12,5 & 10,0 & positivo \\
\hline 23 & 6,0 & 6,5 & 0,5 & 7,0 & 12,4 & 5,4 & 4,9 & positivo \\
\hline 24 & 5,3 & 6,5 & 1,2 & 9,0 & 18,0 & 9,0 & 7,8 & positivo \\
\hline 25 & 6,5 & 7,0 & 0,5 & 7,5 & 12,0 & 4,5 & 4,0 & positivo \\
\hline 26 & 7,6 & 12 & 4,4 & 11,0 & 23,0 & 12,0 & 7,6 & positivo \\
\hline 27 & 6,0 & 6,5 & 0,5 & 9,0 & 14,0 & 5,0 & 4,5 & positivo \\
\hline 28 & 4,5 & 7,0 & 2,5 & 7,3 & 18,0 & 10,7 & 8,2 & positivo \\
\hline 29 & 6,1 & 8,0 & 1,9 & 7,0 & 14,0 & 7,0 & 5,1 & positivo \\
\hline 30 & 5,0 & 12,0 & 7,0 & 7,0 & 21,0 & 14,0 & 7,0 & positivo \\
\hline 31 & 8,5 & 11,0 & 2,5 & 8,5 & 18,5 & 10,0 & 7,5 & positivo \\
\hline 32 & 9,4 & 9,8 & 0,4 & 9,5 & 20,0 & 10,5 & 10,1 & positivo \\
\hline 33 & 7,7 & 10,5 & 2,8 & 9,1 & 19,0 & 9,9 & 7,1 & positivo \\
\hline 34 & 7,0 & 7,5 & 0,5 & 8,5 & 13,5 & 5,0 & 4,5 & positivo \\
\hline 35 & 5,6 & 8,5 & 2,9 & 9,0 & 18,6 & 9,6 & 6,7 & positivo \\
\hline 36 & 5,7 & 8,5 & 2,8 & 7,5 & 14,4 & 6,9 & 4,1 & positivo \\
\hline 37 & 4,8 & 7,5 & 2,7 & 8,3 & 15,7 & 7,4 & 4,7 & positivo \\
\hline 38 & 6,7 & 10,5 & 3,8 & 7,5 & 17,2 & 9,7 & 5,9 & positivo \\
\hline 39 & 5,6 & 6,0 & 0,4 & 8,0 & 13,0 & 5,0 & 4,6 & positivo \\
\hline 40 & 7,0 & 7,5 & 0,5 & 7,0 & 15,8 & 8,8 & 8,3 & positivo \\
\hline
\end{tabular}

$\mathrm{A}=$ purified protein derivative (derivado proteico purificado) $(\mathrm{PPD})$ aviária; $\mathrm{B}=\mathrm{PPD}$ bovino; $\mathrm{AO}$ e $\mathrm{BO}=$ medida inicial da dobra da pele. $\mathrm{A}$ diferença de cada medida é expressa por $\Delta \mathrm{A}$ e $\Delta \mathrm{B}$, e o resultado final é obtido por meio da média final das duas medidas $\Delta \mathrm{B}-\Delta \mathrm{A}$. 
absorbância da amostra/positivo (A/P). Amostras com relação $\mathrm{A} / \mathrm{P}$ igual ou maior que 0,30 foram consideradas positivas para anticorpos contra $M$. bovis, e as amostras com relaçáo A/P inferior a 0,30 foram consideradas negativas (WATERS et al., 2011).

O diagnóstico molecular foi realizado pela técnica de PCR. A extração do DNA genômico das amostras de swab nasal foi feita conforme protocolo adaptado (BIASE et al., 2002). Empregaram-se os primers JB21 e JB22 (RodrigueZ et al., 1999), que amplificam um fragmento de $500 \mathrm{pb}$, localizado em uma regiáo do genoma de 4.999 pb na extremidade 3' do gene RvD1-Rv2031c, que não está presente em outras espécies de micobactérias. A amplificação deu-se em concordância com o seguinte protocolo: tampão de reação 1X [200 mM Tris- $\mathrm{HCl} \mathrm{pH} \mathrm{8.4;} 500 \mathrm{mM} \mathrm{KCl];} \mathrm{0,2} \mathrm{mM} \mathrm{de}$ dNTPs [dCTP, dATP, dGTP, dTTP]; $\mathrm{MgCl}_{2} 2 \mathrm{mM}$; primers JB21/JB22 5 pmol/uL; Taq DNA polimerase $5 \mathrm{U} / \mu \mathrm{L} ; \mathrm{DNA}$ total $6 \mu \mathrm{L}$; água MilliQ q.s.p. $20 \mu \mathrm{L}$.

O DNA puro da cepa padrão AN5 de $M$. bovis foi utilizado como controle positivo. O programa usado no aparelho termociclador SelectCycler (BioProducts) para amplificação do fragmento de DNA de $M$. bovis foi: desnaturação inicial a $94^{\circ} \mathrm{C}$ por 5 min seguida por 37 ciclos de 1 min a $94^{\circ} \mathrm{C}, 1 \mathrm{~min}$ a $64^{\circ} \mathrm{C}$ e $1 \mathrm{~min}$ a $72^{\circ} \mathrm{C}$, com extensão final a $72^{\circ} \mathrm{C}$ por $7 \mathrm{~min}$. Os produtos resultantes da PCR foram analisados por eletroforese em gel de agarose $1,5 \%$ corado com o corante SYBR ${ }^{\circledR}$ Safe gel stain 10.000X (Invitrogen) $0,5 \mathrm{uL} / 10 \mathrm{~mL}$.

A pesquisa foi aprovada pelo Comitê de Ética na Utilização de Animais (CEUA) da Universidade Federal de Uberlândia (UFU), sob o protocolo de n. ${ }^{\circ}$ 054/12.

\section{RESULTADOS E DISCUSSÃO}

Por meio da inspeção sanitária, verificou-se que, das 40 carcaças avaliadas, 22 (55\%) apresentaram algum tipo de lesão macroscópica sugestiva de tuberculose. Os linfonodos mediastínicos foram os que tiveram maior ocorrência (14/40), seguidos do fígado (7/40) e do pulmão (6/40). As lesōes visualizadas foram nódulos granulomatosos de aspecto purulento ou caseoso, com presença de cápsula fibrosa, e em alguns casos apresentaram ainda calcificaçáo no centro da lesão, evidenciada pela crepitação da faca ao corte. Em $15 \%$ dos casos, observou-se ainda hiperplasia dos linfonodos mediastínicos (Fig. 1).

A sensibilidade encontrada (55\%) foi inferior à reportada por FráGUAs et al. (2008), que constataram 72,16\% das carcaças com lesóes, e superior à relatada por PinTo et al. (2004), que depararam com $44 \%$ dos bovinos reagentes à tuberculinização. Considerando que $58 \%$ dos animais infectados com tuberculose exibem lesóes únicas (Corner et al.,
1990), a inspeção mais detalhada de linfonodos, incluindo os da cabeça, os torácicos e os mesentéricos, bem como baço, rim, úbere e órgãos genitais, aumenta a possibilidade de tais lesôes virem a ser visualizadas (CorNer, 1994).

A inspeção macroscópica não detectou lesões sugestivas de tuberculose em 18 (45\%) carcaças. Situaçóes em que os bovinos positivos aos testes tuberculínicos não contenham lesôes visíveis à necropsia podem ocorrer (FIRDEsSA et al., 2012). Alguns aspectos estariam envolvidos, tais como: os animais estarem no estágio inicial da doença, contato com outras micobactérias que não o $M$. bovis, pequena quantidade de bacilos no tubérculo, contato com outros bacilos álcool-ácido resistentes, vacas em final de gestação, bezerros que ingeriram leite de vaca tuberculosa, presença de impurezas na tuberculina, incapacidade de interpretação do teste, além de infecçôes intercorrentes com bactérias pseudotuberculosas, como Corynebacterium pseudotuberculosis (TRYLICH, 1960; Souza et al., 1999). Fora isso, o tempo destinado para a inspeçáo de abate pode ser insuficiente para detectar todas as lesōes, o que dificulta o exame mais detalhado (Corner, 1994).

Nos achados histopatológicos visualizados em HE, verificou-se que 13 (32,5\%) carcaças apresentaram alteraçóes histológicas, sendo elas encontradas com maior frequência nos linfonodos mediastínicos (15\%), seguidos pelo fígado $(12,5 \%)$ e pulmáo $(7,5 \%)$. Foi observada a presença de granulomas típicos de tuberculose em alguns casos, envolvidos por cápsula fibrosa, com um centro de necrose caseosa ou de
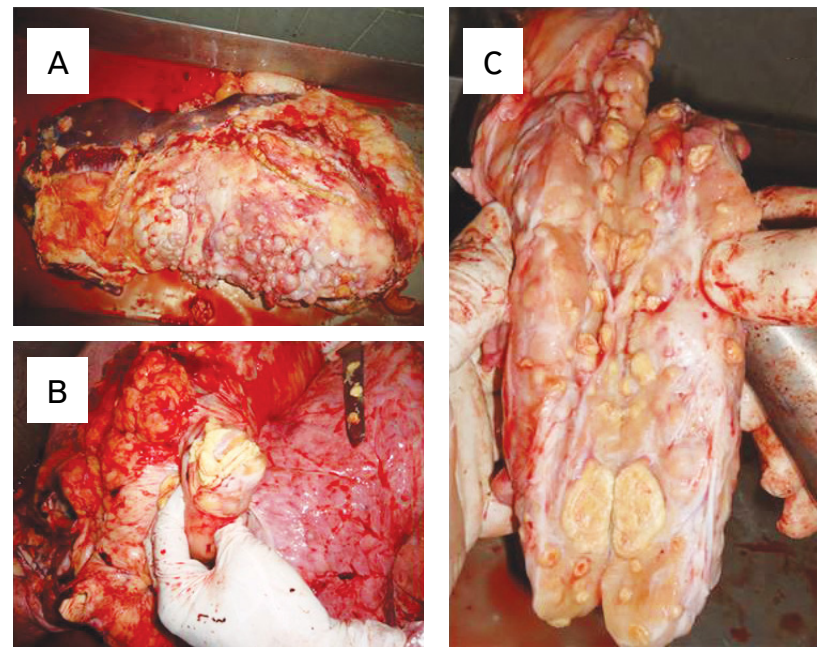

Figura 1. Lesões nodulares típicas de tuberculose em órgãos de bovinos positivos no teste cervical comparativo. São Gotardo, MG, 2012. (A) Fígado com aspecto de tuberculose miliar, apresentando lesões nodulares de 1 a $3 \mathrm{~cm}$ de diâmetro. (B) Pulmão com lesão nodular com cerca de $4 \mathrm{~cm}$ de diâmetro, de cor amarelada, envolvido por cápsula fibrosa e contendo exsudato com aspecto caseoso em seu interior. (C) Aumento de volume de linfonodo mediastínico com processo inflamatório granulomatoso contendo exsudato de aspecto caseoso a purulento em seu interior. 
calcificação circundado por intensa proliferação de células mononucleares, células gigantes de Langhans e zona circunscrita de linfócitos (Fig. 2).

Das 22 lesôes consideradas positivas no exame macroscópico, 13 foram confirmadas pelo exame histopatológico corado em HE. Em oito animais $(20 \%)$ as lesões macroscópicas semelhantes à tuberculose constatadas nos linfonodos não se confirmaram no exame histopatológico. Essa diferença pode ser explicada pela ocorrência de processos inflamatórios granulomatosos determinados por outras etiologias, com características macroscópicas indiferenciáveis da tuberculose, como o linfossarcoma, as linfadenites inespecíficas, a actinobacilose e a nocardiose (Reis et al., 1995; Roxo, 1997).

Além disso, o fato de nem todas as lesôes macroscópicas terem sido confirmadas no exame histopatológico HE pode ter sido em funçáo da subjetividade no julgamento de tais lesóes durante a inspeção sanitária (Reis et al., 1995). Por essa razão, a inspeção das carcaças deve ser realizada de forma criteriosa, por profissionais bem treinados, para diminuir o risco de alimentos duvidosos chegarem à mesa dos consumidores ou, ainda, segundo Fráguas et al. (2008), a real etiologia e prevalência de lesões granulomatosas não tuberculosas requerem ampla atenção por representarem motivo de condenação desnecessária de carcaças e, muitas vezes, induzirem ao erro durante os procedimentos de inspeção.

As alteraçôes histológicas encontradas em apenas 13 carcaças podem ser justificadas pelos vários estágios de evolução da infecção. A resposta imune é diferente em infecçôes recentes e avançadas, o que suporta a identificação entre os animais crônica ou recentemente infectados (Medeiros et al., 2012). Medeiros et al. (2012) empregaram o exame histopatológico e outros testes
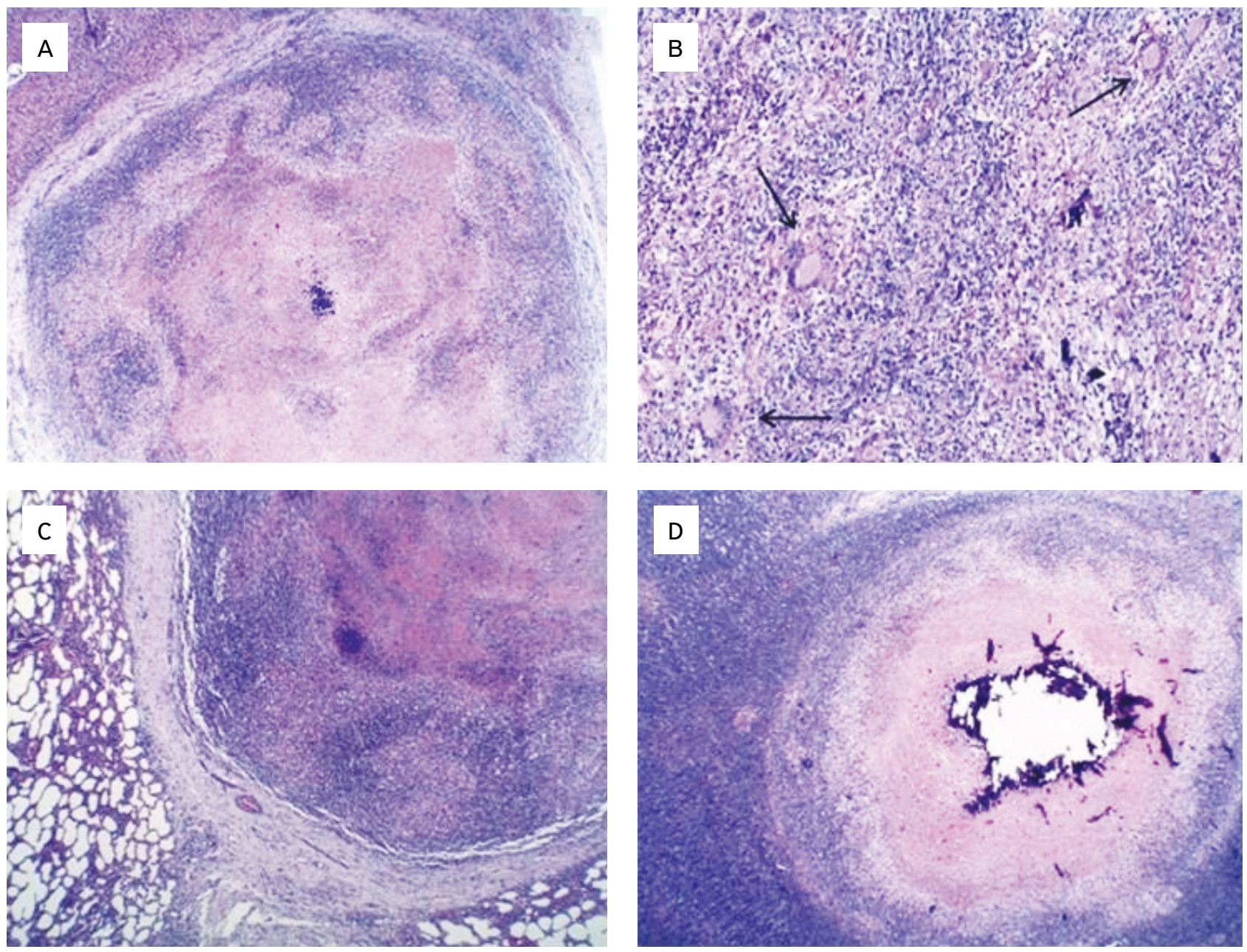

Figura 2. Fotomicrografia de amostras de fígado, pulmão e linfonodo mediastínico de bovinos positivos no teste cervical comparativo obtidas em abate sanitário para tuberculose bovina. São Gotardo, MG, 2012. (A) Secção de fígado. Granuloma envolvido por tecido conjuntivo fibroso, com área central de necrose caseosa com foco de calcificação. Hematoxilina-eosina (HE). 5x (B) Parênquima hepático, as setas indicam células gigantes do tipo Langhans. Citoplasma amplo e núcleos dispostos na periferia da célula em forma de ferradura. HE. 40x. (C) Secção de pulmão. Granuloma tuberculoso circundado por espessa cápsula fibrosa. Necrose caseosa central com infiltrado de células monoclueares. HE. 5x. (D) Secção de linfonodo evidenciando estrutura granulomatosa com área de necrose central e calcificação distrófica HE. 5x. 
complementares para identificação dos estágios da fisiopatologia da tuberculose e concluíram que nem todos os animais doentes de um rebanho se encontram na mesma fase de infecção.

Não foi observada a presença de BAAR em nenhuma das amostras avaliadas pela coloração de ZN. Embora a técnica seja considerada um exame básico em tuberculose humana, sobretudo do escarro, ela não é tão sensível no diagnóstico histopatológico da tuberculose animal, pois os bacilos nem sempre são visualizados na amostra, mesmo na presença de lesôes (Fráguas et al., 2008).

Outros estudos demonstraram também baixa sensibilidade da técnica de ZN quando aplicada em cortes histológicos. Andrade et al. (1991) observaram BAAR em 9,1\% das amostras histológicas examinadas. Salazar (2005) e FurLANETto et al. (2012) relataram ausência de BAAR em amostras de tecidos com lesóes sugestivas de tuberculose, confirmadas no exame histopatológico. Esses resultados podem ser justificados pelo fato de o teste só conseguir revelar a presença de BAAR em concentraçôes superiores a $10^{4}$ bactérias (RODRIGUEZ et al., 2004).

Entre as 40 amostras de soro analisadas pelo ELISA Mycobacterium bovis Antibody Test IDEXX ${ }^{\circledast}$, apenas um $(2,5 \%)$ animal foi positivo, com valor de densidade óptica igual a 0,333 e relaçáo A/P superior a 0,30. Esperava-se maior número de animais reagentes, principalmente entre as amostras que apresentaram lesóes granulomatosas de tuberculose, uma vez que anticorpos são desenvolvidos em estágios mais avançados da doença e estão relacionados com o progresso da infecçáo (Pollock; Neill, 2002; Welsh et al., 2005; Pollock et al., 2005). Além disso, a baixa sensibilidade encontrada pode ter sido causada por conta de problemas relacionados à sensibilidade e especificidade dos testes sorológicos, que variam em função dos antígenos empregados no ensaio (Strain et al., 2011) e da ocorrência de reaçôes cruzadas com outras espécies de micobactérias (Morrison et al., 2000).

WATERS et al. (2011) verificaram 63\% de sensibilidade no ELISA/IDEXX ${ }^{\circledast}$ em soro sanguíneo de bovinos reagentes aos testes de tuberculinização intradérmica e/ou histopatológico e/ou cultura. Conforme WATERs et al. (2011), a sensibilidade do ELISA/IDEXX ${ }^{\circledR}$ aumenta com a severidade da doença, porém no presente estudo se verificou que, apesar da existência de alteraçôes patológicas caracterizadas por lesóes anatomopatológicas generalizadas, presente em mais de $50 \%$ das carcaças, e da hiperplasia de linfonodos, o ELISA/IDEXX ${ }^{\circledR}$ identificou apenas um animal reagente.

O animal reagente no exame sorológico apresentou também lesóes sugestivas de tuberculose no exame macroscópico, que foi confirmado pelo teste histopatológico $\mathrm{HE}$, com lesão do tipo granulomatosa no fígado e no pulmáo. Medeiros et al. (2012) utilizaram ELISA com as proteínas recombinantes
MPB70/MPB83 em bovinos positivos no TCC e constataram que, entre nove animais positivos no teste histopatológico HE, três foram também positivos no ELISA, e, de dez animais considerados inconclusivos no exame histopatológico, dois foram reativos no ELISA.

O fragmento de $500 \mathrm{pb}$ específico de $M$. bovis foi observado em apenas uma amostra de DNA obtida de muco nasal de bovino naturalmente infectado para $M$. bovis. A baixa sensibilidade do exame realizado diretamente por meio de muco nasal pode ser explicada pela possibilidade da pequena quantidade de bacilos presente nas amostras. A recuperação do $M$. bovis mediante técnicas convencionais de cultivo em muco nasal de bovinos naturalmente infectados já foi relatada por outros autores (De Kantor; Roswurm, 1978), com eficiência de recuperação de 8,7\%. A eficiência é baixa, pois para resultado positivo é necessária a presença de 10-100 microrganismos viáveis na amostra (BARRY et al., 1993).

Diferenças importantes no perfil de eliminação do bacilo já foram percebidas, o que classificou os bovinos como eliminadores persistentes ou intermitentes (KAO et al., 2007; Figueiredo et al., 2010). A falha na eliminação da bactéria em animais experimentalmente infectados já foi relatada (Mc Corry et al., 2005). O nível de desprendimento aumenta durante as primeiras quatro semanas após a exposição ao agente e em seguida começa a diminuir (KAO et al., 2007), mas as bactérias ainda podem ser detectadas por várias semanas e em alguns casos durante vários meses (Figueiredo et al., 2010).

Para amplificação do fragmento genômico RvD1-Rv2031c, utilizou-se PCR convencional com os primers JB21 e JB22, que amplificam o fragmento de $500 \mathrm{pb}$. Figueiredo et al. (2010) identificaram o DNA de M. bovis por meio de PCR multiplex, que amplifica simultaneamente as sequências RvD1-Rv2031c (específica para M. bovis) e IS6110 (presente em todas as espécies do complexo Mycobacterium Tuberculosis), e verificaram a presença do DNA de $M$. bovis em duas de 34 (5,9\%) amostras de swab nasal de bovinos reagentes no TCC.

Com o uso da PCR foi possível identificar o DNA de M. bovis em dois dias de trabalho, tempo muito inferior ao necessário para a confirmação pelo método bacteriológico, que pode ser de até 90 dias (Pinto et al., 2002). Tecnologias com base em ácidos nucleicos como a PCR e métodos relacionados têm se mostrado como uma ferramenta de diagnóstico mais rápida e específica (RUGGIERo et al., 2007).

A inspeção macroscópica detalhada das carcaças é uma ferramenta importante na vigilância em abatedouros, auxiliando na identificação de lesóes sugestivas de tuberculose. O exame histopatológico das lesôes tem boa especificidade e permite a confirmação da presença da lesão granulomatosa. 
Conclui-se que entre os exames complementares de diagnóstico avaliados nenhum foi capaz de detectar todos os animais que estavam positivos na tuberculinização, porém a associação de diferentes métodos pode garantir a confiabilidade no diagnóstico. Apesar dos problemas relacionados à especificidade do teste intradérmico, ele é considerado uma ferramenta útil e eficaz na identificação de animais doentes e no controle da tuberculose bovina, uma vez que a resposta imune predominante na tuberculose é a celular.

\section{AGRADECIMENTOS}

Os autores agradecem o apoio financeiro das agências de fomento à pesquisa no Brasil: Conselho Nacional de Desenvolvimento Científico e Tecnológico (CNPq), juntamente com o Ministério da Agricultura Pecuária e Abastecimento (MAPA) e a Secretaria de Defesa Agropecuária (SDA), a aprovaçấo do Edital n. ${ }^{\circ}$ 64/2008 CNPq/MAPA/DAS; e à Fundação de Amparo à Pesquisa do Estado de Minas Gerais (FAPEMIG). REFERÊNCIAS

AAGAARD, C.; GOVAERTS, M.; MEIKLE, V.; GUTIÉRREZ-PABELLO, J.A.; MCNAIR, J.; ANDERSEN, P.; SUÁREZ-GÜEMES, F.; POLLOCK, J.; ESPITIA, C.; CATALDI, A. Detection of bovine tuberculosis in herds with different disease prevalence and influence of paratuberculosis infection on PPDB and ESAT-6/CFP10 specificity. Preventive Veterinary Medicine, v.96, n.3-4, p.161-169, 2010. DOI: $10.1016 /$ j.prevetmed.2010.06.007

ANDRADE, G.B.; RIET-CORREA, F.; MIELKE, P.V.; MÉNDEZ, M.C.; SCHILD, A.L. Estudo histológico e isolamento de micobactérias de lesões similares à tuberculose em bovinos no Rio Grande do Sul. Pesquisa Veterinária Brasileira, v. 1 1, n.3-4, p.81-86, 1991.

BARRY, T.; GLENNON, M.; SMITH, T.; GANNON, F. Detection of Mycobacterium bovis in bovine blood by combined PCR and DNA probe methods. Veterinary Record, v.132, n.3, p.66-67, 1993. DOI: $10.1136 / v r .132 .3 .66$

BIASE, F.H.; FRANCO, M.M.; GOULART, L.R.; ANTUNES, R.C. Protocol for extraction of genomic DNA from swine solid tissues. Genetics and Molecular Biology, v.25, n.3, p.313-315, 2002. DOI: $10.1590 / \mathrm{S} 1415-47572002000300011$

BRASIL. Ministério da Agricultura. Regulamento da Inspeção Industrial e Sanitária de Produtos de Origem Animal. Brasília, 1962.

CORNER, L.A. Post mortem diagnosis of Mycobacterium bovis infection in cattle. Veterinary Microbiology, v.40, n.1-2, p.53-63, 1994.

CORNER, L.A.; MELVILLE, L.; MCCUBBIN, K.; SMALL, K.J.; MCCORMICK, B.S.; ROTHEL, J.S. Efficiency of inspection procedures for detection of tuberculosis lesions in cattle. Australian Veterinary Journal, v.67, n.11, p.389-392, 1990.

DE KANTOR, I.N.; ROSWURM, J.D. Mycobacteria isolated from nasal secretions of tuberculin test reactor cattle. American Journal of Veterinary Research, v.39, n.7, p.1233-1234, 1978.

FIGUEIREDO, E.E.S.; CARVALHO, R.C.T.; SILVESTRE, F.G.; LILENBAUM, W.; FONSECA, L.S.; SILVA, J.T.; PASCHOALIN, V.M.F. Detection of Mycobacterium bovis DNA in nasal swabs from tuberculosis cattle by a multiplex PCR. Brazilian Journal of Microbiology, v.41, n.2, p.386-390, 2010.DOI: 10.1590/S1517-83822010000200020
FIRDESSA, R.; TSCHOPP, R.; WUBETE, A.; SOMBO, M.; HAILU, E.; ERENSO, G.; KIROS, T.; YAMUAH, L.; VORDERMEIER, M.; HEWINSON, R.G.; YOUNG, D.; GORDON, S.V.; SAHILE, M.; ASEFFA, A.; BERG, S. High prevalence of bovine tuberculosis in dairy cattle in Central Ethiopia: implications for the dairy industry and public health. Plos One, v.7, n.12, p.1-12, 2012. DOI: 10.1371/ journal.pone.0052851

FRÁGUAS, S.A.; CUNHA-ABREU, M.S.; FERREIRA, A.M.R.; MARASSI, C.D.; OELEMANN, W.; FONSECA, L.S.; FERREIRA, R.; LILENBAUM, W. Estudo comparativo de métodos complementares para o diagnóstico da tuberculose bovina em animais reagentes à tuberculinização. Revista Brasileira de Ciências Veterinárias, v. 15, n.3, p.117-121, 2008.

FURLANETTO, L.V.; FIGUEIREDO, E.E.S; CONTE JÚNIOR, C.A.; CARVALHO, R.C.T.; SILVA, F.G.S.; SILVA, J.T.; LILENBAUM, W.; PASCHOALIN, V.M.F. Uso de métodos complementares na inspeção post mortem de carcaças com suspeita de tuberculose bovina. Pesquisa Veterinária Brasileira, v.32, n.1 1, p.1138-1144, 2012.

JONES, T.C.; HUNT, R.D.; KING, N.W. Patologia veterinária. 6. ed. São Paulo: Manole, 2000.

KAO, R.R.; GRAVENOR, M.B.; CHARLESTON, B.; HOPE, J.C.; MARTIN, M.; HOWARD, C.J. Mycobacterium bovis shedding patterns from experimentally infected calves and the effect of concurrent infection with bovine viral diarrhoea virus. Journal of the Royal Society Interface, v.4, n. 14, p.545-551, 2007. DOI: 10.1098/rsif.2006.0190

MC CORRY, T.; WHELAN, A.O.; WELSH, M.D.; MCNAIR, J.; WALTON, E.; BRYSON, D.G.; HEWINSON, R.G.; VORDERMEIER, H.M.; POLLOCK, J.M. Shedding of Mycobacterium bovis in the nasal mucus of cattle infected experimentally with tuberculosis by the intranasal and intratracheal routes. Veterinary Records, v. 157, n.26, p.613-618, 2005. DOI: $10.1136 / v r .157 .20 .613$

MEDEIROS, L.; MARASSI, C.D.; FIGUEIREDO, E.E.S.; LILENBAUM, W. Potential application of new diagnostic methods for controlling bovine tuberculosis in Brazil. Brazilian Journal of Microbiology, v.41, n.3, p.531-541, 2010. DOI: 10.1590/ S1517-83822010005000002 
MEDEIROS, L.S.; MARASSI, C.D.; FIGUEIREDO, E.E.S.; LEITE, J.; FERREIRA, A.M.R.; LILENBAUM, W. Assessing the histopathology to depict the different stages of bovine tuberculosis infection in a naturally infected herd. Pesquisa Veterinária Brasileira, Rio de Janeiro, v.32, n.2, p.135-139, 2012. DOI: 10.1590/ S0 $100-736 \times 2012000200008$

MICHEL, A.L.; MÜLLER, B.; VAN HELDEN, P.D. Mycobacterium bovis at the animal-human interface: a problem, or not? Veterinary Microbiology, v. 140, n.3-4, p. 371-381, 2010. DOI: 10.1016/j. vetmic.2009.08.029

MONAGHAN, M.L.; DOHERTY, M.L.; COLLINS, J.D.; KAZDA, J.F.; QUINN, P.J. The tuberculin test. Veterinary Microbiology, v.40, n. 1-2, p.111-124, 1994.

MORRISON, W.I.; BOURNE, F.J.; COX, D.R.; DONNELLY, C.A.; GETTINBY, G.; MCINERNEY, J.P.; WOODROFFE, R. Pathogenesis and diagnosis of infection with Mycobacterium bovis in cattle. Veterinary Record, v.146, n.9, p.236-242, 2000.

OFFICE INTERNATIONAL DES EPIZOOTIES (OIE). Bovine tuberculosis. In: _. Manual of diagnostic tests and vaccines for terrestrial animals 2015. 2015. Chapter 2.4.6. Disponível em: <http://www.oie.int/fileadmin/Home/eng/Health_standards/ tahm/2.04.06_BOVINE_TB.pdf>. Acesso em: 9 out. 2016.

PINTO, P.S.A.; FARIA, J.E.; VILORIA, M.I.V.; BEVILACQUA, P.D. Exame microbiológico da tuberculose como subsídio à inspeção post-mortem de bovinos. Revista Brasileira de Saúde e Produção Animal, v.3, n.1, p.10-15, 2002.

PINTO, P.S.A.; VILORIA, M.I.V.; FARIA, J.E. Avaliação do desempenho dos exames anatomopatológico e histopatológico na inspeção post mortem de bovinos suspeitos ou reagentes à prova de tuberculinização. Revista Brasileira de Ciência Veterinária, v.11, n. 1-2, p.27-31, 2004.

POLLOCK, J.M.; NEILL, S. D. Mycobacterium bovis infection and tuberculosis in cattle. The Veterinary Journal, v.163, n.2, p. $115-127,2002$.

POLLOCK, J.M.; WELSH, M.D.; MCNAIR, J. Immune responses in bovine tuberculosis: towards new strategies for the diagnosis and control of disease. Veterinary Immunology and Immunopathology, v.108, n.1-2, p.37-43, 2005. DOI: 10.1016/j. vetimm.2005.08.012

REIS, D.O.; ALMEIDA, L.; FARIA, A.R. Estudo comparativo entre linfossarcoma, tuberculose e linfadenites inespecíficas ocorridas em bovinos abatidos e a confirmação histológica. Higiene Alimentar, v.9, n.35, p.28-30, 1995.

RODRIGUEZ, C.A.R.; ZUMÁRRAGA, M.J.; OLIVEIRA, E.M.D.; CATALDI, A.A.; ROMANO, M.I.; OTTO, H.H.; BONAFÉ, V.L.; FERREIRA NETO, J.S. Caracterização molecular de isolados de Mycobacterium bovis do estado de São Paulo Brasil, utilizando a técnica de Spoligotyping. Arquivos do Instituto Biológico, São Paulo, v.71, n.3, p.277-282, 2004.

RODRÍGUEZ, J.G.; FISSANOTI, J.C.; DEL PORTILLO, P.; PATARROYO, M.E.; ROMANO, M.I.; CATALDI, A. Amplification of a 500-base pair fragment from cultured isolates of Mycobacterium bovis. European Journal of Clinical Microbiology and Infectious Diseases, v.37, n.7, p.2330-2332, 1999.

ROXO, E. Mycobacterium bovis como causa de zoonose. Revista de Ciências Farmacêuticas, v. 18, n. 1, p.101-108, 1997.

RUGGIERO, A.P.; IKUNO, A.A.; FERREIRA, V.C.A.; ROXO, E. Tuberculose bovina: alternativas para o diagnóstico. Arquivos do Instituto Biológico, v.74, n. 1, p.55-65, 2007.

SALAZAR, F.H.P. Ocorrência de tuberculose causada por Mycobacterium bovis em bovinos abatidos em frigoríficos no estado de Mato Grosso, Brasil. 2005. 73f. Dissertação (Mestrado) - Universidade Federal de Mato Grosso do Sul, Campo Grande, 2005.

SOUZA, A.V.; SOUSA, C.F.A.; SOUZA, R.M.; RIBEIRO, R.M.P.; OLIVEIRA, A.L. A importância da tuberculose bovina como zoonose. Higiene Alimentar, v.13, n.59, p.22-27, 1999.

STRAIN, S.A.J.; MCNAIR, J.; MCDOWELL, S.W.J. Bovine tuberculosis: a review of diagnostic tests for $M$. bovis infection in badgers. Agri-food and Biosciences Institute, 2011.

TOLOSA, E.M.C.; RODRIGUES, C.J.; BEHMER, O.A.; FREITAS NETO, A.G. Manual de técnicas para histologia normal e patológica. 2. ed. São Paulo: Manole, 2003.

TRYLICH, C. Diagnosis and no visible lesions in tuberculosis of cattle. Canadian Veterinary Journal, v.1, n. 12, p.545-550, 1960.

WATERS, W.R.; BUDDLE, B.M.; VORDERMEIER, H.M.; GORMLEY, E.; PALMER, M.V.; THACKER, T.C.; BANNANTINE, J.P.; SATBEL, J.R.; LINSCOTT, R.; MARTEL, E.; MILIAN, F.; FOSHAUG, W.; LAWRENCE, J.C. Development and evaluation of an enzyme-linked immunosorbent assay for use in the detection of bovine tuberculosis in cattle. Clinical and Vaccine Immunology, v. 18, n. 1 1, p.1882-1888, 2011.

WATRELOT-VIRIEUX, D.; DREVON-GAILLOT, E.; TOUSSAINT, Y.; BELLI, P. Comparison of three diagnostic detection methods for tuberculosis in French cattle. Journal of Veterinary Medicine $B$, Infectious Disease and Veterinary Public Health, v.53, n.7, p.321-325, 2006. DOI: $10.1111 /$ j.1439-0450.2006.00957.x

WELSH, M.D.; CUNNINGHAM, R.T.; CORBETT, D.M.; GIRVIN, R.M.; MCNAIR, J.; SKUCE, R.A.; BRYSON, D.G.; POLLOCK, J.M. Influence of pathological progression on the balance between cellular and humoral immune responses in bovine tuberculosis. Immunology, v. 114 , n. 1, p.101-111, 2005. DOI: 10.1111/j.1365-2567.2 004.02003.x 